\section{Response to: "The incretins - outdated terminology in man? By C. M. B. Edwards and S. R. Bloom, London, UK"}

Dear Sir,

Edwards and Bloom righteously point out that it is experimentally difficult to prove an incretin role for glucagon-like peptide 1 (GLP-1) in humans. They argue that it is more important to judge a therapeutic ("antidiabetogenic") potential than to elucidate the underlying mechanism or to assess incretin functions. This is, from a pharmacotherapeutic point of view, true. There is, however, a basic scientific interest in elucidating the physiological role of gut hormones like gastric inhibitory polypeptide (GIP) and GLP-1, which together contribute approximately $50 \%$ of the insulin response after an oral glucose load $[1,2]$. Therefore, there is no doubt about an important incretin effect, and it is my guess that GIP is much more of an incretin than GLP-1. Unfortunately, GIP has little if any effects in Type II (non-insulin-dependent) diabetic patients $[3,4]$. On the other hand, the interest that GLP-1 has received as a potential new treatment for Type II diabetes does not necessarily derive from the function that GLP-1 has in a healthy organism. Dismissing GLP-1 as an incretin hormone does not invalidate the therapeutic trials that are coming up with promising analogues.

There is one aspect where I have a different view: Edwards and Bloom mention "the impossibility of assessment of the incretin effect" and use the multiplicity of actions of GLP-1 to explain why blocking one GLP-1 action leads to secondary changes in other variables (e.g. the acceleration of gastric emptying leads to an enhanced insulin and glucagon response due to a more rapid absorption of nutrients), which in turn might affect plasma glucose independently of any direct effects of GLP-1. While this is true and would require a great number of control experiments (e.g. intraduodenal instead of oral delivery of nutrients, "clamping" of glycaemic concentrations etc.) for clarification, I still would like to know the overall ef-

Corresponding author: M. Nauck, Medizinische Universitätsklinik, Knappschafts-Krankenhaus, In der Schornau 23-25, D-44892 Bochum, Germany fect of injecting GLP-1 [5] or of blocking its actions [6] to judge a net action profile.

GLP-1 is of much more interest as a potential pharmacological agent [7]. Its physiological and pathophysiological role in normal humans and several diseased states (impaired glucose tolerance and Type II diabetes, reactive hypoglycaemia, malassimilation, and others), however, still deserves attention. It appears too early to give up on these issues.

Yours sincerely,

M. Nauck, MD

\section{References}

1. Nauck MA, Homberger E, Siegel EG et al. (1986) Incretin effects of increasing glucose loads in man calculated from venous insulin and C-peptide responses. J Clin Endocrinol Metab 63: 492-498

2. Tillil H, Shapiro ET, Miller A et al. (1988) Dose-dependent effects of oral and intravenous glucose on insulin secretion and clearance in normal humans. Am J Physiol (Endocrinol Metab) 254: E349-E357

3. Jones IR, Owens DR, Moody AJ, Luzio SD, Morris T, Hayes TM (1987) The effects of glucose-dependent insulinotropic polypeptide infused at physiological concentrations in normal subjects and Type II (non-insulin-dependent) diabetic patients on glucose tolerance and B-cell secretion. Diabetologia 30: 707-712

4. Nauck MA, Heimesaat MM, Ørskov C, Holst JJ, Ebert R, Creutzfeldt W (1993) Preserved incretin activity of glucagon-like peptide 1 [7-36 amide] but not of synthetic human gastric inhibitory polypeptide in patients with type-2 diabetes mellitus. J Clin Invest 91: 301-307

5. Nauck MA, Niedereichholz U, Ettler R et al. (1997) Glucagon-like peptide 1 inhibition of gastric emptying outweighs its insulinotropic effects in healthy humans. Am J Physiol 273: E981-E988

6. Edwards CMB, Todd JF, Mahmoudi M et al. (1999) GLP1 has a physiological role in the control of postprandial glucose in man. Studies with the antagonist exendin 9-39. Diabetes 48: 86-93

7. Nauck MA, Holst JJ, Willms B, Schmiegel W (1997) Glucagon-like peptide 1 (GLP-1) as a new therapeutic approach for Type 2-diabetes. Exp Clin Endocrinol Diabetes 105: 187-195 